\title{
Correction: Computing the T-matrix of a scattering object with multiple plane wave illuminations
}

\author{
Martin Fruhnert ${ }^{* 1}$, Ivan Fernandez-Corbaton ${ }^{2}$, Vassilios Yannopapas ${ }^{3}$ \\ and Carsten Rockstuhl ${ }^{1,2}$
}

\section{Correction}

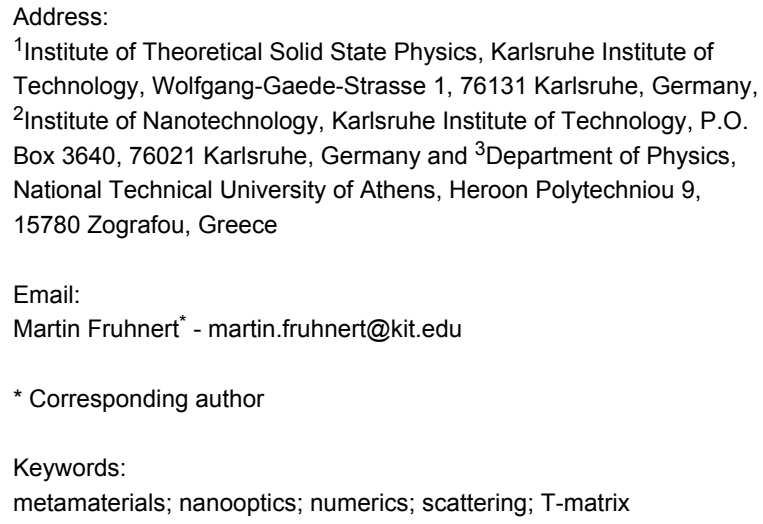

${ }^{1}$ Institute of Theoretical Solid State Physics, Karlsruhe Institute of Technology, Wolfgang-Gaede-Strasse 1, 76131 Karlsruhe, Germany, ${ }^{2}$ Institute of Nanotechnology, Karlsruhe Institute of Technology, P.O. Box 3640, 76021 Karlsruhe, Germany and ${ }^{3}$ Department of Physics, National Technical University of Athens, Heroon Polytechniou 9, 15780 Zografou, Greece

Email:

Martin Fruhnert ${ }^{\star}$ - martin.fruhnert@kit.edu

* Corresponding author

Keywords:

metamaterials; nanooptics; numerics; scattering; T-matrix

Beilstein J. Nanotechnol. 2018, 9, 953. doi:10.3762/bjnano.9.88

Received: 27 February 2018

Accepted: 09 March 2018

Published: 22 March 2018

Guest Editor: H. Hahn

(C) 2018 Fruhnert et al.; licensee Beilstein-Institut. License and terms: see end of document.

This correction refers to Beilstein J. Nanotechnol. 2017, 8, 614-626. doi:10.3762/bjnano.8.66

In the original publication, the unnumbered equation that appears in the top right corner on page 624 before Equation 23 contains an error. The order of the svd vectors should be as follows:

$$
\sigma_{-}=\left(\operatorname{svd}\left[\mathbf{T}_{--}^{\text {helicity }}\right] \operatorname{svd}\left[\mathbf{T}_{+-}^{\text {helicity }}\right]\right)
$$

The authors would like to acknowledge Mr. Philipp Gutsche for pointing out this error.

\section{License and Terms}

This is an Open Access article under the terms of the Creative Commons Attribution License (http://creativecommons.org/licenses/by/4.0), which permits unrestricted use, distribution, and reproduction in any medium, provided the original work is properly cited.

The license is subject to the Beilstein Journal of Nanotechnology terms and conditions: (https://www.beilstein-journals.org/bjnano)

The definitive version of this article is the electronic one which can be found at:

doi:10.3762/bjnano.9.88 